\title{
Damien Agut-Labordere, "The agricultural landscape of Ayn Manawir (Kharga Oasis, Egypt) through the Persian period ostraca (vth-ivth century BC)"
}

\section{Rémy Boucharlat}

\section{(2) OpenEdition}

\section{Journals}

Édition électronique

URL : http://journals.openedition.org/abstractairanica/48173

DOI : 10.4000/abstractairanica.48173

ISBN : 1961-960X

ISSN : 1961-960X

Éditeur :

CNRS (UMR 7528 Mondes iraniens et indiens), Éditions de l'IFRI

\section{Référence électronique}

Rémy Boucharlat, « Damien Agut-Labordere, "The agricultural landscape of Ayn Manawir (Kharga Oasis, Egypt) through the Persian period ostraca (vth-ivth century BC)" », Abstracta Iranica [En ligne] Volume 40-41 | 2019, document 11, mis en ligne le 15 juillet 2019, consulté le 24 avril 2021. URL http://journals.openedition.org/abstractairanica/48173; DOI : https://doi.org/10.4000/ abstractairanica.48173

Ce document a été généré automatiquement le 24 avril 2021.

Tous droits réservés 


\title{
Damien Agut-Labordere, “The agricultural landscape of Ayn Manawir (Kharga Oasis, Egypt) through the Persian period ostraca (vth-ivth century BC)"
}

\author{
Rémy Boucharlat
}

\section{RÉFÉRENCE}

Damien Agut-Labordere, "The agricultural landscape of Ayn Manawir (Kharga Oasis, Egypt) through the Persian period ostraca (vth-ivth century BC)" in Louise Purdue, Julien Charbonnier, Lamya Khalidi (eds). From refugia to oases. Living in arid environments from prehistoric times to the present day/Des refuges aux oasis/Vivre en milieu aride de la Préhistoire à aujourd'hui, (actes des XXXVIIIe Rencontres internationales d'Archéologie et d'Histoire d'Antibes, oct. 2017). 2018, Antibes : Ed. APDCA, p. 359-377

1 L'importance du site d'Ayn Manâwir dans l'oasis de Kharga est maintenant reconnue pour l'étude de l'exploitation agricole dans un village, à partir de l'époque perse, principalement du milieu du Ve et au milieu du IVe s. av. J.-C., puis à l'époque romaine, non traitée ici. Cette importance est due à étude soigneuse du système de courtes galeries d'eau, appelées localement qanât, mais tout autant aux centaines d'ostraca trouvés sur le site dont beaucoup traite des pratiques agricoles: «jours d'eau", pratique typique de l'agriculture en milieu aride, dont l'oasis, reçus et ordres de livraisons de produits. Ces documents, ici pourtant rapidement écrits, parfois incomplets, sont cependant légaux, très importants pour réguler la vie socioéconomique. Les ostraca fournissent aussi quelque 70 hydronymes, puits ou sources ou débouchés d'eau portant des noms de personnes, parfois membres d'une même famille, qui passent contrat entre eux pour une vente d'eau ou une délimitation de terrain, des 
changements qui sont souvent commandés par l'évolution, en général négative, des ressources en eau.

\section{AUTEURS}

\section{RÉMY BOUCHARLAT}

UMR 5133 CNRS-Université de Lyon 